\title{
Effects of Sitagliptin May Depend on Clinical and Laboratory Data at the Baseline
}

\author{
Hidekatsu Yanai ${ }^{a, b, c}$
}

\section{To the Editor}

We have previously reported that the 6-month sitagliptin treatment significantly reduced $\mathrm{HbA} 1 \mathrm{c}$, body weight in Japanese patients with type 2 diabetes [1]. We also found a negative correlation between changes in body weight and body mass index (BMI) at baseline, and also reported a negative correlation between changes in $\mathrm{HbAlc}$ and $\mathrm{HbAlc}$ levels at baseline [1].

Kubota $\mathrm{A}$ et al reported that the 12 weeks-sitagliptin treatment significantly decreased $\mathrm{HbA1c}$, serum total cholesterol and postprandial triglyceride levels, systolic blood pressure and diastolic blood pressure, and also increased serum creatinine [2]. However, we could not observe significant differences in systolic and diastolic blood pressure, and serum lipid levels, and estimated glomerular filtration rate (e-GFR) between before and after the sitagliptin treatment [1].

The mean \pm SD of age $(63.3 \pm 11.5)$ in the study by Kubota A et al was younger than that $(64.0 \pm 14.0)$ in our study $[1,2]$. Aging influences pharmacokinetics and pharmacodynamics. To understand how age influences effects of sitaglitpin, we analyzed data by dividing subjects studied into patients who are 75 years old or older (the elderly group, $\mathrm{n}=54$ ) and patients who are 74 years old or younger (the young group, $\mathrm{n}=166$ ). Age ranged from 22 to 74 years old and from 75 to 91 years old, and 83 and 32 female patients were included in the young group and the elderly group, re-

\footnotetext{
Manuscript accepted for publication June 12, 2013

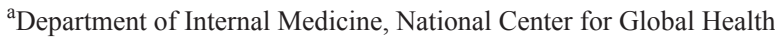
and Medicine, Kohnodai Hospital, Chiba 272-8516, Japan

${ }^{\mathrm{b}}$ Clinical Research Center, National Center for Global Health and Medicine, Kohnodai Hospital, Chiba 272-8516, Japan

${ }^{\mathrm{c} C}$ Corresponding author: Hidekatsu Yanai, Department of Internal Medicine and Clinical Research Center, National Center for Global Health and Medicine, Kohnodai Hospital, 1-7-1 Kohnodai, Chiba 272-8516, Japan. Email: dyanai@hospk.ncgm.go.jp
}

doi: http://dx.doi.org/10.4021/jem171w spectively. The mean \pm SD of age and BMI were $58.0 \pm 12.0$ years old and $27.0 \pm 5.4 \mathrm{~kg} / \mathrm{m}^{2}$, and $81.0 \pm 5.0$ years old and $23.2 \pm 4.0 \mathrm{~kg} / \mathrm{m}^{2}$ in the young group and the elderly group, respectively. In the young group, sitagliptin significantly reduced plasma glucose levels in addition to reduction in body weight and HbAlc which were observed in the previous study (Table 1) [1]. In the elderly group, sitaglitpin significantly reduced $\mathrm{HbAlc}$, however, did not show a significant reduction of body weight which was observed in the previous study (Table 2) [1].

Differences in changes in clinical and biochemical data after 6 month-use of sitagliptin between the young group and the elderly group were shown in Table 3. Sitagliptin showed greater decrease of body weight, systolic blood pressure, plasma glucose and $\mathrm{HbAlc}$, and also showed smaller decrease of serum levels of low-density lipoprotein cholesterol and high-density lipoprotein cholesterol, and e-GFR in the young group as compared with the elderly group.

In conclusion, our previous study and present study demonstrated that effects of sitagliptin may depend on clinical data such as age and BMI and laboratory data such as $\mathrm{HbAlc}$ at the baseline.

\section{Acknowledgement}

The authors would like to thank Tomoko Kaga, Yukari Takano, Fumi Kawasaki, Yukie Kawamura, and Naomi Inoue at Clinical Research Center, National Center for Global Health and Medicine Kohnodai Hospital, for their technical help. This work was supported by the Grant of National Center for Global Health and Medicine (22-120).

\section{References}

1. Yanai H, Adachi H, Hamasaki H, Masui Y, Yoshikawa R, Moriyama S, Mishima S, et al. Effects of 6-month sitagliptin treatment on glucose and lipid metabolism, blood pressure, body weight and renal function in type 2 diabetic patients: a chart-based analysis. J Clin Med Res. 2012;4(4):251-258. 
Table 1. Clinical and Biochemical Data Before and After 6 Month-Use of Sitagliptin in 166 People Who are 74 Years Old or Younger

\begin{tabular}{|c|c|c|c|c|}
\hline & $\begin{array}{l}\text { Subjects studied } \\
\text { (n) }\end{array}$ & $\begin{array}{l}\text { Data before } 6 \\
\text { month-use of } \\
\text { sitagliptin }\end{array}$ & $\begin{array}{l}\text { Data after } 6 \\
\text { month-use of } \\
\text { sitagliptin }\end{array}$ & $P$ value \\
\hline Body weight (kg) & 110 & $71.6 \pm 15.2$ & $70.7 \pm 15.5$ & $<0.01$ \\
\hline Systolic blood pressure (mmHg) & 124 & $126.1 \pm 15.3$ & $124.6 \pm 13.2$ & NS \\
\hline Diastolic blood pressure $(\mathrm{mmHg})$ & 124 & $71.7 \pm 12.2$ & $72.7 \pm 10.6$ & NS \\
\hline Plasma glucose (mg/dL) & 154 & $190.9 \pm 71.6$ & $176.2 \pm 67.8$ & $<0.01$ \\
\hline Hemoglobin A1c (\%) & 132 & $7.8 \pm 1.3$ & $7.2 \pm 1.2$ & $<0.05$ \\
\hline Serum LDL-C (mg/dL) & 129 & $105.8 \pm 30.3$ & $103.2 \pm 28.8$ & NS \\
\hline Serum TG (mg/dL) & 144 & $192.7 \pm 126.7$ & $187.3 \pm 136.8$ & NS \\
\hline Serum HDL-C (mg/dL) & 136 & $48.9 \pm 13.2$ & $47.7 \pm 11.0$ & NS \\
\hline $\mathrm{e}-\mathrm{GFR}\left(\mathrm{mL} / \mathrm{min} . / 1.73 \mathrm{~m}^{2}\right)$ & 155 & $80.5 \pm 24.7$ & $79.5 \pm 25.9$ & NS \\
\hline
\end{tabular}

Presented values indicate mean \pm S.D. Statistical analyses have been done by the paired T test; e-GFR, estimated glomerular filtration rate; HDL, high-density lipoprotein; LDL-C, low-density lipoprotein-cholesterol; NS, not statistically significant; TG, triglyceride.

Table 2. Clinical and Biochemical Data Before and After 6 Month-Use of Sitagliptin in 54 People Who are 75 Years Old or Older

$\begin{array}{lll}\text { Subjects studied } & \begin{array}{l}\text { Data before } 6 \\ \text { month-use of } \\ \text { (n) }\end{array} & \begin{array}{l}\text { Data after } 6 \text { month- } \\ \text { use of sitagliptin }\end{array}\end{array} \quad$ P value

\begin{tabular}{lllll}
\hline Body weight $(\mathrm{kg})$ & & $56.3 \pm 11.8$ & $55.7 \pm 10.8$ & NS \\
Systolic blood pressure (mmHg) & 45 & $128.4 \pm 16.1$ & $126.9 \pm 14.6$ & NS \\
Diastolic blood pressure (mmHg) & 45 & $65.4 \pm 10.2$ & $65.2 \pm 10.0$ & NS \\
Plasma glucose (mg/dL) & 42 & $167.2 \pm 54.6$ & $173.2 \pm 65.1$ & NS \\
Hemoglobin Alc (\%) & 37 & $7.3 \pm 1.1$ & $6.8 \pm 1.0$ & $<0.05$ \\
Serum LDL-C (mg/dL) & 37 & $101.6 \pm 24.3$ & $101.9 \pm 20.5$ & NS \\
Serum TG (mg/dL) & 40 & $126.1 \pm 81.5$ & $126.0 \pm 84.1$ & NS \\
Serum HDL-C (mg/dL) & 41 & $55.0 \pm 17.5$ & $53.6 \pm 17.7$ & NS \\
e-GFR (mL/min./1.73m $\left.{ }^{2}\right)$ & 45 & $66.5 \pm 19.8$ & $63.2 \pm 18.5$ & NS \\
\hline
\end{tabular}

Presented values indicate mean \pm S.D. Statistical analyses have been done by the Wilcoxon signed-rank test; e-GFR, estimated glomerular filtration rate; HDL, high-density lipoprotein; LDL-C, low-density lipoprotein-cholesterol; NS, not statistically significant; TG, triglyceride.

2. Kubota A, Maeda H, Kanamori A, Matoba K, Jin Y, Minagawa F, Obana M, et al. Pleiotropic effects of si- tagliptin in the treatment of type 2 diabetes mellitus patients. J Clin Med Res. 2012;4(5):309-313. 
Table 3. Differences in Changes in Clinical and Biochemical Data After 6 Month-Use of Sitagliptin Between People Who are 74 Years Old or Younger and People Who are 75 Years Old or Older

\begin{tabular}{llll}
\hline & $\begin{array}{l}\text { People who are } \\
\text { 74 years old or } \\
\text { younger }\end{array}$ & $\begin{array}{l}\text { People who are 75 } \\
\text { years old or older }\end{array}$ & P value \\
\hline Body weight $(\mathrm{kg})$ & $-0.9 \pm 3.9$ & $-0.6 \pm 2.7$ & $<0.001$ \\
Systolic blood pressure (mmHg) & $-1.5 \pm 15.3$ & $-1.4 \pm 23.0$ & $<0.05$ \\
Diastolic blood pressure (mmHg) & $+1.0 \pm 12.2$ & $-0.2 \pm 13.0$ & $\mathrm{NS}$ \\
Plasma glucose (mg/dL) & $-14.8 \pm 68.9$ & $+6.0 \pm 74.0$ & $<0.05$ \\
Hemoglobin A1c (\%) & $-0.6 \pm 1.0$ & $-0.4 \pm 0.7$ & $<0.001$ \\
Serum LDL-C (mg/dL) & $-2.5 \pm 26.7$ & $-9.0 \pm 33.2$ & $<0.05$ \\
Serum TG (mg/dL) & $-5.4 \pm 141.2$ & $-0.1 \pm 44.2$ & $\mathrm{NS}$ \\
Serum HDL-C (mg/dL) & $-1.2 \pm 8.3$ & $-1.4 \pm 10.1$ & $<0.001$ \\
e-GFR (mL/min./1.73m $\left.{ }^{2}\right)$ & $-1.0 \pm 12.5$ & $-3.2 \pm 9.4$ & $<0.01$ \\
\hline
\end{tabular}

Presented values indicate mean \pm S.D. Statistical analyses have been done by the $Z$ test; e-GFR, estimated glomerular filtration rate; HDL, high-density lipoprotein; LDL-C, low-density lipoprotein-cholesterol; NS, not statistically significant; TG, triglyceride. 